\title{
Composite Converter of Hybrid Storage in Distributed Renewable Energy Generation System
}

\author{
Bo Dong, Yongdong Li, Zhixue Zheng \\ Department of Electrical Engineering, Tsinghua University \\ Beijing, China, 10084 \\ E-mail: dongb07@mails.tsinghua.edu.cn
}

\begin{abstract}
This paper focuses on a kind of composite converter which is used to connect batteries and super-capacitor in distributed renewable energy generation system. The composite converter can transfer energy in hybrid storage system between batteries and super-capacitor to keep the stability of system when one of them has low or high state of charge (SOC). Also the composite converter can make batteries' SOC balanced by choosing switches after the batteries in series are used for a long time. Structure and operation principle of composite converter are described in the paper. Also simulation results are shown with Matlab/Simulink.
\end{abstract}

\section{INTRODUCTION}

Batteries in series connected have been used widely, such as electric vehicles, hybrid electric vehicles, microgrid system with distributed renewable energy generations and so on. Because of variant of manufactures and working environment, aging, thermal difference, imbalance between charging and discharging, and differences in internal impedances and selfcharging rate, the energy (or charge) stored in cells are not equal [1]. Because all the cells are in series, the battery performance is limited to the weakest cell. In the worst case, when SOC of one battery is very low and SOC of another is very high, the battery pack nearly can't be used. These battery mismatches reduce the lifetime, efficiency, and capacity of the battery. So equalization of SOC is very important for seriesconnected batteries.

There are many equalization methods. References [2, 3] focus on a kind of dissipative method, which is simple but with high loss. Switched capacitor method is described in [47]. Control is easy and batteries can work in both recharging and discharging operation with this method. But energy is transferred from one cell to the adjacent one, so equalization time is long. Multi Bi-DC-DC converter method is described in [8-10], which can control every cell to charge or discharge. But cost of multi Bi-DC-DC converters is high because there are many switching devices and inductors. Reference [11] focuses on multi-winding transformer method. The circuit of this method is complex and cost is high. Modularized charge equalization method in [12] can charge any cell in a battery pack which is used for a large number of cells, but the equalization time is long.

Although battery has low price and high energy density, but it can't absorb or release power very quickly. So supercapacitor is needed as fast energy storage to reduce the influence of power fluctuation, especially in renewable energy generation system. Super-capacitor has advantage of high power density, high cycle life and large charging or discharging current [13]. But its cost is much higher than leadacid battery. So a hybrid storage system is needed including batteries and super-capacitor.

A DC- and AC-bus microgrid system with distributed renewable energy generations is established in the lab which consists of wind turbine $(2 \mathrm{KW})$, photovoltaic panels $(1 \mathrm{KW})$, super-capacitor $(72 \mathrm{~V}, 70 \mathrm{~F})$ and batteries (one battery is $12 \mathrm{~V}$, $65 \mathrm{AH}$ and six batteries are connected in series) as shown in Fig. 1. Both batteries and super-capacitor are connected to DC bus with an isolated DC-DC converter. Also there is a kind of composite converter between batteries and super-capacitor. For Energy Management System (EMS) of microgrid system, it is very important to keep voltage of DC- and AC- bus stable $[14,15]$. In islanded operation in order to make local loads working steadily, the hybrid storage system must be controlled to absorb or release power difference between renewable energy generations and local loads by EMS. According to characters of hybrid storages, super-capacitor is used to absorb or release high frequency power and batteries are used for long time storage. However super-capacitor can only store very little energy, so it is usually out of charge which will lead hybrid storage system to lose the ability of response to high frequency power. It is very dangerous especially in islanded operation. With composite converter, energy can be transferred between batteries and super-capacitor. So when super-capacitor has low or high SOC, it can absorb or release energy with batteries until SOC is normal. Meanwhile, after a long time usage, SOC of batteries will be different. Because all the batteries are connected in series, the battery performance is limited to the weakest one. The Composite Converter is also used to make batteries charge equalization through choosing switches.

In this paper, section II introduces the structure, principles of operation and control strategy of the composite converter. Section III shows simulation results. Section IV concludes the full paper.

\section{COMPOSITE CONVERTER}

\section{A. Structure of Composite Converter}

The composite converter includes a Bi-DC-DC converter, positive and negative switches as shown in Fig. 2. Bi-DC-DC 


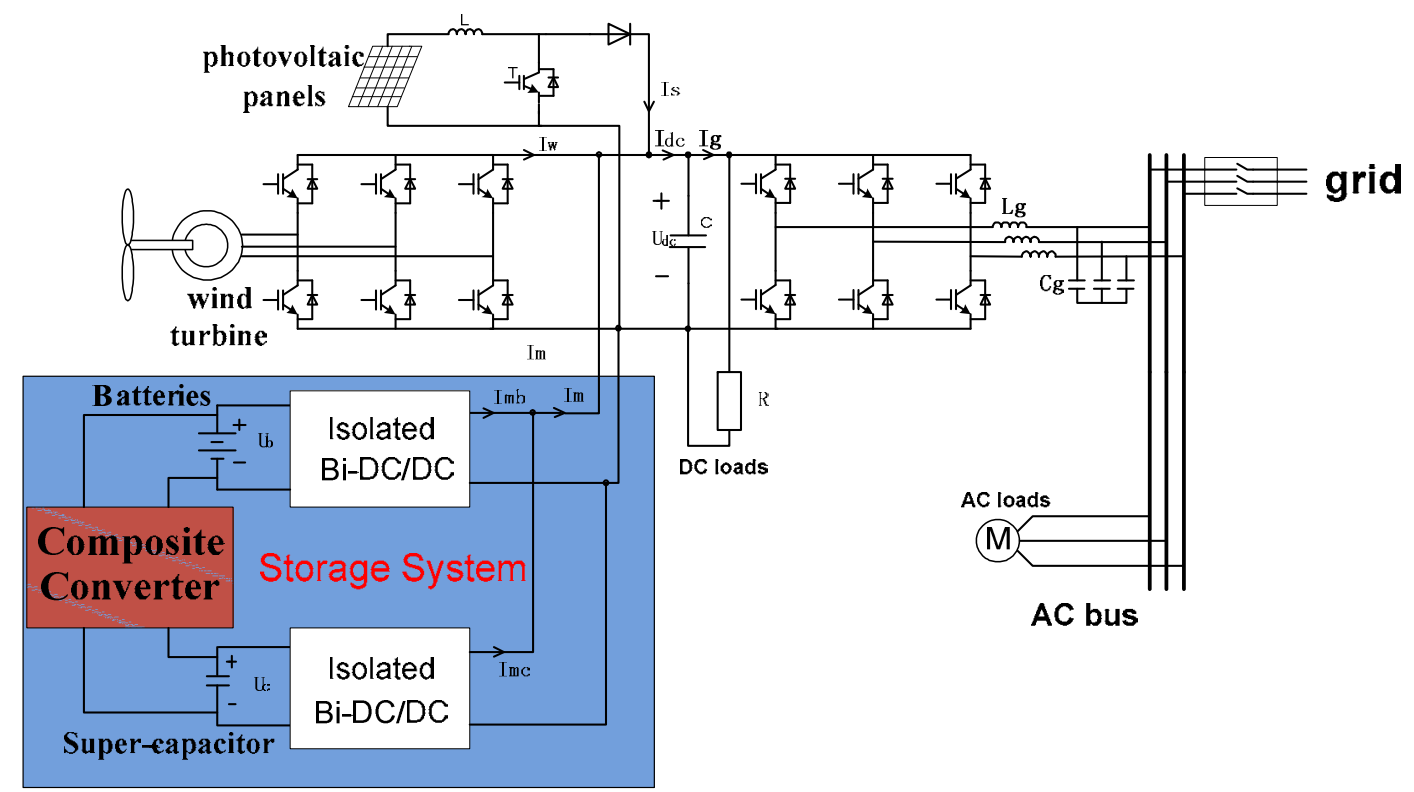

Fig. 1. Microgrid system with hybrid DC- and AC-bus

converter is used to transfer energy between batteries and super-capacitor according to SOC of them. There are six batteries in the hybrid storage system, and each battery has a pair of switches. All the positive switches are connected to positive output of converter, and all the negative switches are connected to negative pole of super-capacitor.

\section{Positive Switches}

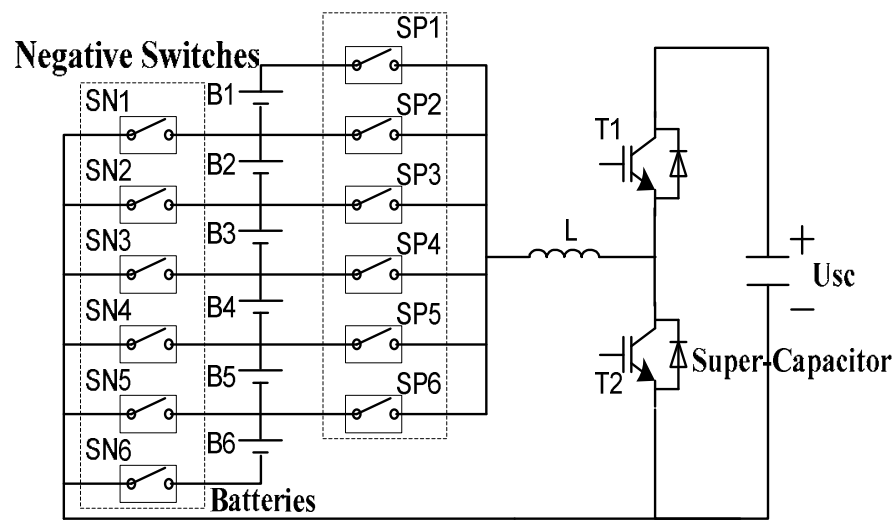

Fig. 1. Structure of Composite Converter

\section{B. Operation Principle of Composite Converter}

The composite converter can be used to balance SOC of batteries by controlling the switches. When SOC of battery is lower than $30 \%$, it is in low zone. If SOC is between $30 \%$ and $85 \%$, it is normal. And it is in high zone when SOC of battery is higher than $85 \%$. Different control strategies will be used in different zones [16]. In order to avoid oscillation at the threshold, hysteresis control is used as shown in Fig. 3. For example, when battery is charging, high SOC zone is defined that SOC of battery must be higher than $90 \%$. And if battery discharging from high to normal, SOC must be lower than $80 \%$. SOC of battery can't be calculated directly from the voltage of positive and negative poles when the battery is working. Several methods for estimating SOC of battery are described in $[17,18]$.

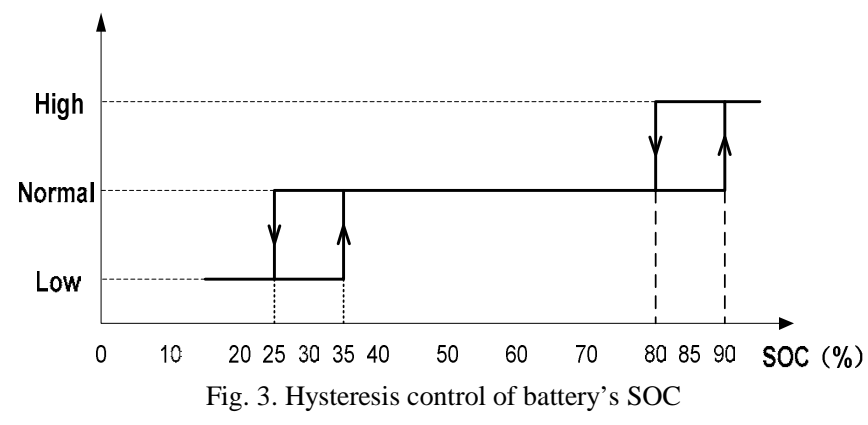

State of charge of super-capacitor can be calculated in (1). Just like battery, when SOC of super-capacitor is lower than $20 \%$, it is in low zone. If SOC is between $20 \%$ and $90 \%$, it is normal. And it is in high zone when SOC of super-capacitor is higher than $90 \%$. Also different control strategies will be used in different zones. Hysteresis control of super-capacitor is used as shown in Fig. 4.

$$
S O C_{s c}=\frac{\frac{1}{2} C U_{s c}{ }^{2}}{\frac{1}{2} C U^{2}{ }_{s c_{-} \text {rating }}}=\frac{U_{s c}^{2}}{U_{s c-\text { rating }}^{2}}
$$

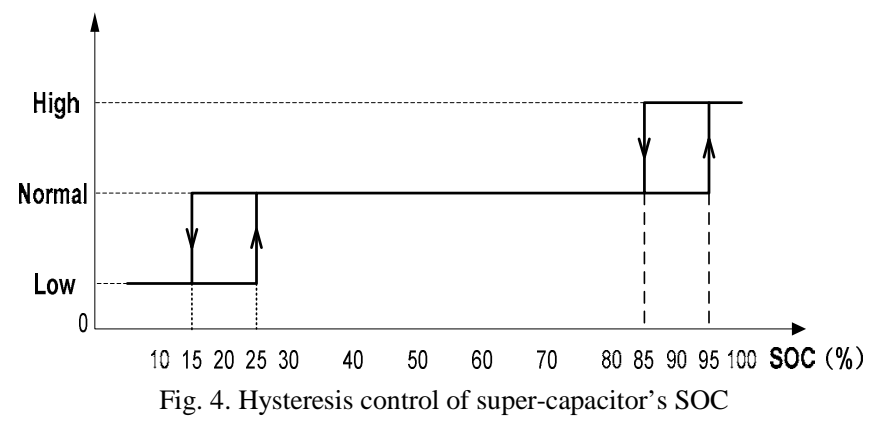

If SOC of $\mathrm{Bi}(\mathrm{i}=1,2, \ldots)$ is higher, EMS controls positive switch SPi and negative switch SNi on, and others off. In this 
case, $\mathrm{Bi}$ connects to the converter and transfers energy to super-capacitor. And then super-capacitor will release energy to the lower battery through converter by choosing the switches until SOC of all the batteries are equal. So EMS could control super-capacitor and composite converter to balance the SOC of all the batteries in battery pack as a buffer. Suppose the SOC difference of batteries is not very large, super-capacitor has the storage capability to finish the equalization.

Meanwhile, composite converter can regulate SOC of super-capacitor. If SOC of super-capacitor is high, EMS will control switches to choose one or several batteries which have low SOC. Energy will be transferred from super-capacitor to chosen batteries until SOC of super-capacitor is normal. If SOC of super-capacitor is low, EMS will choose one battery with high SOC to connect to converter. The battery will transfer energy to super-capacitor until SOC of supercapacitor is normal. When SOC of super-capacitor becomes a little higher, more batteries can be chosen to charge for supercapacitor.

\section{Control Strategy of $\mathrm{Bi}-\mathrm{DC} / \mathrm{DC}$}

If SOC of super-capacitor is high or one of batteries is in low SOC zone, composite converter transfers energy from super-capacitor to the battery. It is a buck converter. Batteries can be charged with constant voltage or constant current. If the battery discharges deeply, charging method with constant current will be used. The block diagram is shown in Fig. 5. Otherwise the battery will be charged with constant voltage as shown in Fig. 6.

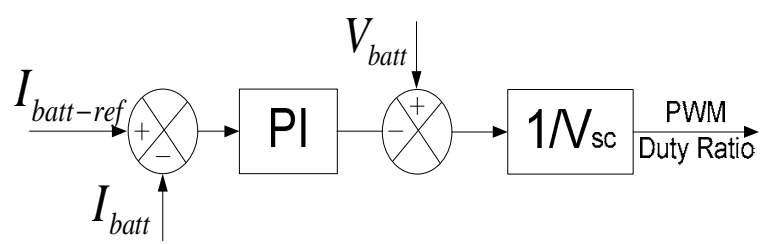

Fig. 5. Block diagram of charging for battery with constant current

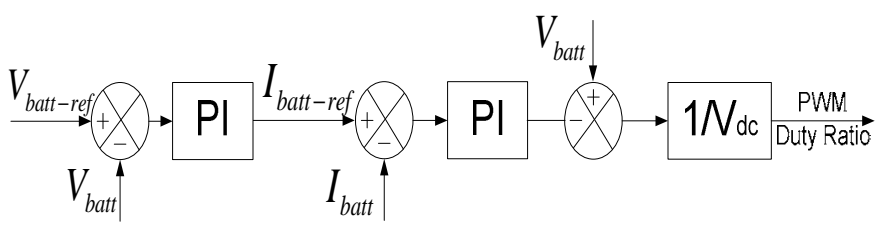

Fig. 6. Block diagram of charging for battery with constant voltage

When SOC of super-capacitor is low or one of batteries is in high SOC zone, the battery will discharge through composite converter. It is a boost converter. The device IGBT connects to super-capacitor directly, so constant charging current for super-capacitor can't be controlled. But charging method with constant power can be used if energy loss of converter is ignored. Also super-capacitor can be charged with constant voltage. The block diagram of constant charging power and voltage are shown in Fig. 7 and Fig. 8, respectively.

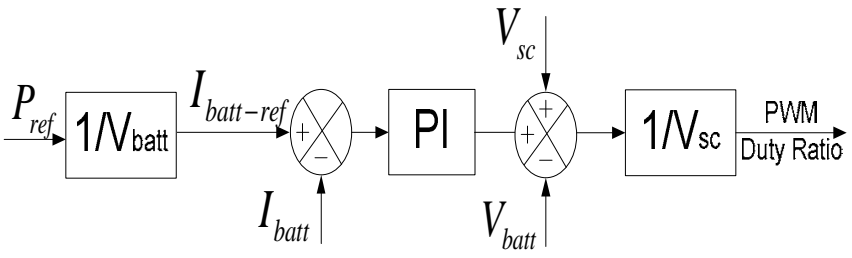

Fig. 7. Block diagram of charging for super-capacitor with constant power

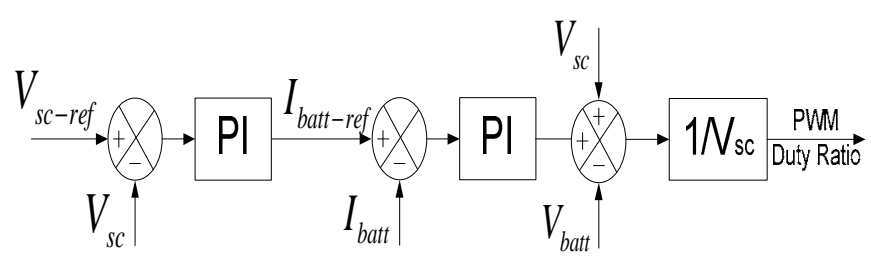

Fig. 8. Block diagram of charging for super-capacitor with constant voltage

\section{Energy Management of Hybrid Storage System}

In the microgrid system, usually there are many renewable energy generations and local loads. In grid-connected operation, when power from renewable energy generations is fluctuant or local loads change quickly, hybrid storage system including batteries and super-capacitor must absorb or release power difference very fast. According to the characters of battery and super-capacitor, EMS controls super-capacitor to absorb or release high frequency power as a fast storage, and battery to absorb or release low frequency power as a longtime storage [19]. Control strategy of hybrid storage system is shown in Fig. 9.

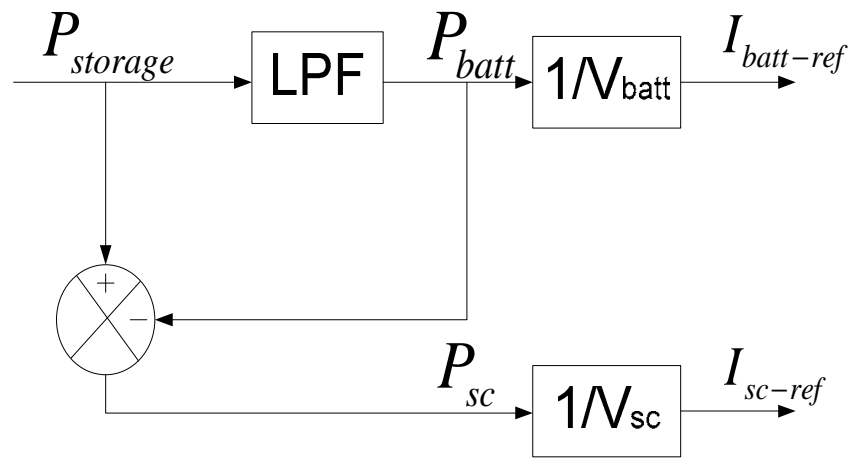

Fig. 9. Control strategy of hybrid storage system

When there are some faults happened in utility grid, mircogrid will work in islanded operation. In this case power difference between renewable energy generations and local loads must be absorbed or released by hybrid storage system. If SOC of batteries or super-capacitor is low or high, composite converter can transfer energy between them. However, in islanded operation if both of them have high SOC and power generated from photovoltaic panels and wind turbine is more than need of local loads, EMS will control photovoltaic panels and wind turbine to replace MPPT operation by load power matching operation. If both of batteries and super-capacitor have low SOC and power from renewable energy generations can't match the need of local loads, the normal loads must be cut from microgrid system in order to keep sensitive loads working. 


\section{SIMULATION RESULTS}

Simulation results of battery equalization with composite converter are shown in Fig. 10 with Matlab/Simulink where we suppose super-capacitor can store enough energy. The initial SOCs of the batteries are $\mathrm{SOC}_{\mathrm{B} 1}=75 \%, \mathrm{SOC}_{\mathrm{B} 2}=66 \%$, $\mathrm{SOC}_{\mathrm{B} 3}=68 \%, \mathrm{SOC}_{\mathrm{B} 4}=70 \%, \mathrm{SOC}_{\mathrm{B} 5}=72 \%, \mathrm{SOC}_{\mathrm{B} 6}=60 \%$.

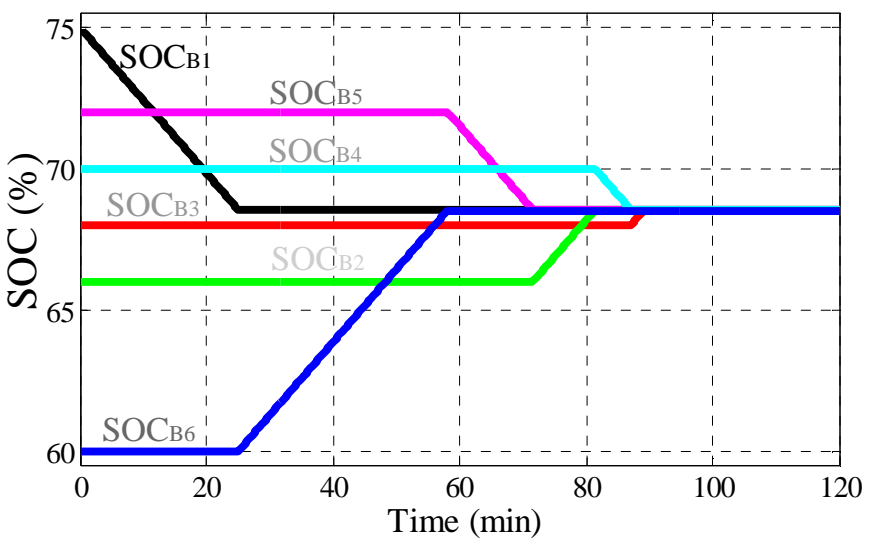

Fig. 10. Simulation results of battery SOC equalization

With control strategy of hybrid storage system, supercapacitor and batteries absorb or release high and low frequency power through the isolated DC-DC, respectively. Fig. 11 shows currents of batteries and super-capacitor when local loads in microgrid system change from $500 \mathrm{~W}$ to $1300 \mathrm{~W}$ at $0.3 \mathrm{~s}$ and from $1300 \mathrm{~W}$ to $800 \mathrm{~W}$ at $0.6 \mathrm{~s}$.

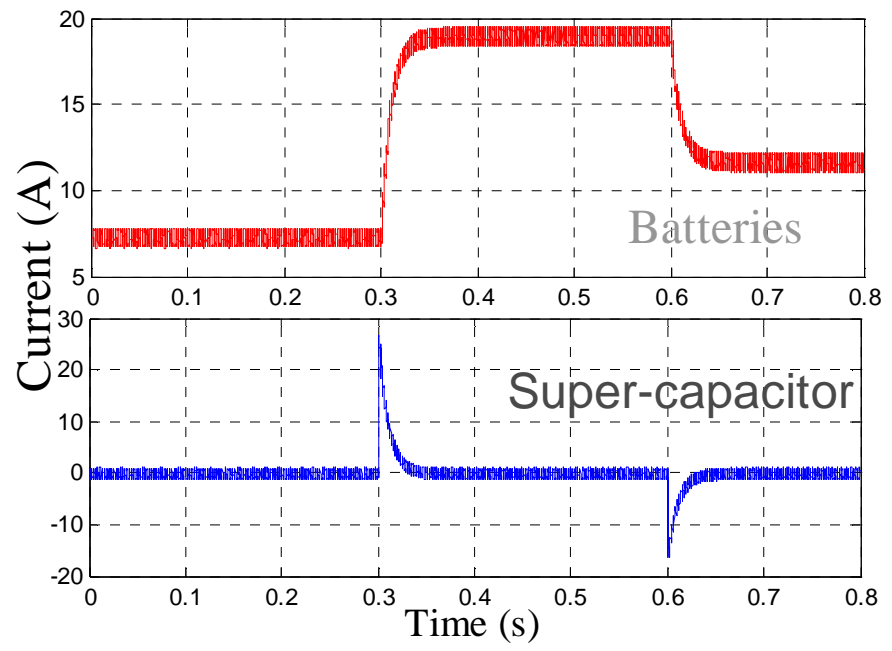

Fig. 11. Current of batteries and super-capacitor

\section{CONCLUSION}

A kind of composite converter is presented in this paper. Structure, operation principle and control strategy are described. With the composite converter, energy can be transferred between batteries and super-capacitor in the hybrid storage system. The composite converter could balance the state of charge of batteries by controlling the switches when SOCs of batteries are different. Also SOC of super-capacitor could be regulated when it is low or high in order to increase the stability of microgrid system, especially in islanded operation. Simulation results verify that SOC equalization of batteries can be finished with the composite converter.

\section{ACKNOWLEDGMENT}

This paper and its related research are supported by grants from the Power Electronics Science and Education Development Program of Delta Environmental \& Educational Foundation.

\section{REFERENCES}

[1] Jian Cao, Schofield, N., Emadi, A.,"Battery balancing methods: A comprehensive review", Vehicle Power and Propulsion Conference, 2008.

[2] Stuart, T.A. , Wei Zhu, "Fast Equalization for Large Lithium Ion Batteries”, Aerospace and Electronic Systems Magazine, IEEE, July 2009, vol. 24, no. 7, pp. 27-31.

[3] B. Lindemark, "Individual cell voltage equalizers (ICE) for reliable battery performance," in Proc. 13th Annu. Int. Telecommun. Energy Conf., Kyoto, Japan, Nov. 1991, pp. 196-201.

[4] Kimball, J.W. , Krein, P.T., "Analysis and design of switched capacitor converters", Applied Power Electronics Conference and Exposition, 2005, vol. 3, pp. 1473-1477.

[5] Kimball, J.W., Kuhn, B.T., Krein, P.T., "Increased Performance of Battery Packs by Active Equalization", Vehicle Power and Propulsion Conference, 2007, pp. 323-327.

[6] Baughman, A.C., Ferdowsi, M.,” Double-Tiered Switched-Capacitor Battery Charge Equalization Technique", Industrial Electronics, IEEE Transactions on, June 2008, vol. 55, no. 5, pp. 2277-2285.

[7] Pascual, C., Krein, P.T., ” Switched Capacitor System for Automatic Series Battery Equalization”, Applied Power Electronics Conference and Exposition, 1997, vol. 2, pp. 848-854.

[8] Chin-Sien Moo, Kong-Soon Ng, Jin-Shin Hu, "Operation of Battery Power Modules with Series Output”, Industrial Technology, 2009, pp. 1-6.

[9] Wei Hong, Kong-Soon Ng, Jin-Hsin Hu, Chin-Sien Moo," Charge Equalization of Battery Power Modules in Series", Power Electronics Conference (IPEC), 2010, vol. 2, pp. 1568-1572.

[10] Moo, C.S., Ng, K.S., Hsieh, Y.C.,” Parallel Operation of Battery Power Modules”, Power Electronics and Drives Systems, 2005, vol. 2, pp. 983-988.

[11] Kutkut, N.H., Wiegman, H.L.N., Divan, D.M., Novotny, D.W.," Charge Equalization for an Electric Vehicle Battery System", Aerospace and Electronic Systems, IEEE Transactions on, Jan 1998, vol. 34, no. 1, pp. 235246

[12] Chol-Ho Kim, Moon-Young Kim, Daeyoun Cho, Gun-Woo Moon, ” A Modularized Charge Equalizer Using Battery Monitoring IC for Series Connected Li-Ion Battery Strings in an Electric Vehicle”, Energy Conversion Congress and Exposition (ECCE), 2010, pp. 3923-3928.

[13] M. Pedram, N. Chang, Y. Kim, and Y. Wang, "Hybrid electrical energy storage systems," in Low-Power Electronics and Design (ISLPED), 2010 ACM/IEEE International Symposium on, 2010, pp. 363-368.

[14] Bilbao, E.; Gaztanaga, H.; Mir, L.; Etxeberria-Otadui, I.; Milo, A.: "Design and development of a supercapacitor-based microgrid dynamic support system," in Power Electronics and Applications, 2009. EPE '09. 13th European Conference on, 2009, pp. 1-10.

[15] J. Zhenhua and Y. Xunwei: "Hybrid DC- and AC-Linked Microgrids: Towards Integration of Distributed Energy Resources," in Energy 2030 Conference, 2008. IEEE, 2008, pp. 1-8.

[16] Z. Tao, L. Peng and B. Francois, "Power management strategies of a DC-coupled hybrid power system in a microgrid for decentralized generation," in Power Electronics and Applications, 2009. EPE '09. 13th European Conference on, 2009, pp. 1-10.

[17] L. Juang, P. Kollmeyer, T. Jahns, and R. Lorenz, "System identification-based lead-acid battery online monitoring system," Energy Conversion Congress and Exposition (ECCE), 2010, pp. 3903-3910.

[18] G. Wu, R. Lu, C. Zhu, and C. C. Chan, "State of charge Estimation for NiMH Battery based on electromotive force method," in Vehicle Power and Propulsion Conference, 2008. VPPC '08. IEEE, 2008, pp. 1-5.

[19] Z. Haihua, T. Bhattacharya, D. Tran, S. S. Tuck, and A. M. Khambadkone, "Composite energy storage system with flexible energy management capability for micro-grid applications," in Energy Conversion Congress and Exposition (ECCE), 2010 IEEE, 2010, pp. 2558-2563. 